\title{
PENGARUH KUALITAS PRODUK DAN CITRA MEREK TERHADAP KEPUASAN PELANGGAN HELM MEREK KYT DI KECAMATAN BINTARA KOTA BEKASI
}

\author{
Berlian Rahmatulah 1) \\ 1) Mahasiswa Program Studi Manajemen FE UNKRIS \\ Ismail Razak 2) \\ 2) Dosen Program Studi Manajemen FE-UNKRIS \\ Alamat: Kampus UNKRIS, Jatiwaringin Jakarta Timur \\ Email: ismailrazak.zain@gmail.com
}

\begin{abstract}
The aim of this study was to analize the influence of product quality and brand image on the satisfaction of customers. Primary data was obtained from customers of helm KYT in Kecamatan Bintara Bekasi City. In this study is used purposive sampling method. Data analysis technique used in this research is simple linear regression and multiple linear regression. The results of this study indicated that product quality and brand image positively and significant influenced the satisfaction of customers.
\end{abstract}

Keywords: Product quality, brand image and satisfaction of customers.

\section{PENDAHULUAN}

Dewasa ini perkembangan bisnis helm di Indonesia mengalami pertumbuhan yang pesat, seiring dengan meningkatnya pengguna kendaraan bermotor roda dua. Oleh karena itu, perkembangan bisnis helm memberikan peluang dan tantangan bagi perusahaan untuk mengembangkan kualitas produk dan menanamkan citra merek helm di benak pelanggan dalam upaya meningkatkan kepuasan pelanggan. Banyak faktor yang menjadikan pelanggan menjadi puas, diantaranya adalah faktor kualitas produk dan citra merek. Khan dan Ahmed (2012), kualitas produk adalah penentu yang paling penting dari kepuasan konsumen. Menurut Jayanti, et al (2018), suatu produk dikatakan berkualitas, apabila produk tersebut mampu memenuhi harapan pelanggan. Citra merek juga merupakan faktor penting yang dapat menentukan kepuasan pelanggan. Menurut Simamora dalam Hafizah
(2012), citra merek merupakan salah satu alat yang penting bagi peritel untuk menarik dan memenuhi kepuasan konsumen (Jayanti, et al; 2018). Banyak hasil penelitian yang menjelaskan hubungan kausalitas antara kualitas produk dan citra merek dengan kepuasan pelanggan, seperti penelitian yang dilakukan oleh Wenur, et al (2015), Diansyah (2016), Saparuddin (2016), Djumarno, et al (2017), Ginantra, et al (2017), dan Jayanti, et al (2018).

Sepeda motor sebagai alat transportasi yang cepat dan efisien sudah tidak dapat dipisahkan lagi dari keseharian sebagian besar masyarakat di Indonesia saat ini. Dengan menggunakan sepeda motor sebagai moda transportasi, kendala waktu dan jarak bagi masyarakat perkotaan yang selalu dalam himpitan kemacetan lalu-lintas dapat diatasi dengan mudah. Di lain pihak, sepeda motor adalah moda transportasi yang memiliki tingkat resiko paling tinggi dalam kecelakaan lalu-lintas dan memiliki tingkat proteksi yang paling 
rendah terhadap pengendara, terutama proteksi terhadap kepala pengendara, yang merupakan asset paling berharga setiap manusia. Seiring dengan meningkatnya jumlah pengendara motor, semakin meningkat tuntutan permintaan helm, sehingga perusahaan akan berupaya meningkatkan kualitas produk dan mempertahankankan citra merek.

Tabel-1. Data Transaksi Penjualan Helm di Bekasi Januari-Mei 2019

\begin{tabular}{llcccccc}
\hline \multirow{2}{*}{ Nama Toko } & \multirow{2}{*}{ Bulan } & \multicolumn{5}{c}{ Merek Helm (Buah) } & \multirow{2}{*}{ Total } \\
\cline { 3 - 7 } & & BMC & INK & KYT & MDS & WTC & \\
\hline Jagoan Helm & Januari & 21 & 18 & 56 & 15 & 12 & $\mathbf{1 2 2}$ \\
& Februari & 24 & 27 & 48 & 24 & 21 & $\mathbf{1 4 4}$ \\
& Maret & 18 & 18 & 60 & 27 & 12 & $\mathbf{1 3 5}$ \\
& April & 33 & 12 & 52 & 27 & 18 & $\mathbf{1 4 2}$ \\
& Mei & 39 & 17 & 73 & 31 & 23 & $\mathbf{1 8 3}$ \\
\hline Kartini Helm & Total & $\mathbf{1 3 5}$ & $\mathbf{9 2}$ & $\mathbf{2 8 9}$ & $\mathbf{1 2 4}$ & $\mathbf{8 6}$ & $\mathbf{7 2 6}$ \\
\hline & Januari & 24 & 18 & 61 & 17 & 13 & $\mathbf{1 3 3}$ \\
& Februari & 27 & 27 & 51 & 25 & 14 & $\mathbf{1 4 4}$ \\
& Maret & 21 & 20 & 63 & 26 & 15 & $\mathbf{1 4 5}$ \\
& April & 36 & 15 & 55 & 27 & 21 & $\mathbf{1 5 4}$ \\
& Mei & 42 & 17 & 76 & 33 & 24 & $\mathbf{1 9 2}$ \\
\hline Amanda Helm & Total & $\mathbf{1 5 0}$ & $\mathbf{9 7}$ & $\mathbf{3 0 6}$ & $\mathbf{1 2 8}$ & $\mathbf{8 7}$ & $\mathbf{7 6 8}$ \\
& Januari & 19 & 17 & 62 & 17 & 11 & $\mathbf{1 2 6}$ \\
& Februari & 25 & 29 & 53 & 23 & 22 & $\mathbf{1 5 2}$ \\
& Maret & 22 & 20 & 61 & 25 & 13 & $\mathbf{1 4 1}$ \\
& April & 34 & 14 & 55 & 28 & 18 & $\mathbf{1 4 9}$ \\
& Mei & 41 & 18 & 72 & 32 & 25 & $\mathbf{1 8 8}$ \\
& Total & $\mathbf{1 4 1}$ & $\mathbf{9 8}$ & $\mathbf{3 0 3}$ & $\mathbf{1 2 5}$ & $\mathbf{8 9}$ & $\mathbf{7 5 6}$ \\
\hline
\end{tabular}

Sumber : Toko penjual helm Mei 2019, diolah

Saat ini, banyak merek helm yang ditawarkan pemasar kepada konsumen. Berdasarkan Tabel-1, transaksi penjualan helm merek KYT di Bekasi lebih banyak dibandingkan dengan merek helm lainnya, artinya diduga kualitas helm merek KYT lebih unggul dibandingkan kualitas merek helm lain, dan merek KYT lebih dikenal dibandingkan merek helm lain. Seiring dengan meningkatnya pengendara motor, tuntutan permintaan akan helm semakin bertambah. Hal ini memotivasi perusahaan untuk terus meningkatkan kualitas produk dan mempertahankankan citra merek.

Berdasarkan penjelasan tersebut, tujuan penelitian ini adalah untuk menganalisis pengaruh kualitas produk dan citra merek terhadap kepuasan pelanggan helm merek KYT di
Kecamatan Bintara Kota Bekasi baik secara parsial maupun secara bersamasama. Hasil penelitian ini diharapkan dapat bermanfaat bagi pengembagan ilmu manajemen pemasaran, terutama yang berkaitan dengan kualitas produk, citra merek dan kepuasan pelanggan. Bagi penelitian selanjutnya diharapkan hasil penelitian ini dapat bermanfaat sebagai referensi, terutama yang berkaitan dengan kualitas produk, citra merek dan kepuasan pelanggan. Bagi pimpinan perusahaan diharapkan hasil penelitian ini dapat bermanfaat sebagai masukan di dalam menetapkan strategi pemasaran, terutama yang berkaitan dengan kualitas produk, citra merek dan kepuasan pelanggan. 


\section{LANDASAN TEORI}

\section{Kepuasan Pelanggan}

Menurut Schiffman dan Kanuk (2004), kepuasan pelanggan adalah persepsi individu terhadap kinerja suatu barang atau jasa dikaitkan dengan harapan pelanggan tersebut, sedangkan menurut Umar, (2005) kepuasan pelanggan adalah tingkat perasaan pelanggan setelah membandingkan antara apa yang dia terima dan harapannya. Selanjutnya, Kotler dan Amstrong (2012) mendefinisikan kepuasan pelanggan adalah sejauh mana kinerja yang dirasakan suatu produk sesuai harapan pembeli, sedangkan Yamit (2013) mengatakan bahwa kepuasan pelanggan merupakan evaluasi purna beli atau hasil evaluasi setelah membandingkan apa yang dirasakan dengan harapnnya.

Berarti, kepuasan pelanggan adalah respon atau tanggapan pelanggan mengenai pemenuhan kebutuhan. Kepuasan merupakan penilaian mengenai ciri atau keistimewaan produk atau jasa, atau produk itu sendiri, yang menyediakan tingkat kesenangan pelanggan berkaitan dengan pemenuhan kebutuhan konsumsi pelanggan. Memuaskan kebutuhan pelanggan adalah keinginan setiap perusahaan. Seorang pelanggan, jika merasa puas dengan nilai yang diberikan oleh suatu produk atau jasa, maka sangat besar kemungkinan menjadi pelanggan dalam waktu yang lama. Selain faktor penting bagi kelangsungan hidup perusahaan, memuaskan kebutuhan pelanggan dapat meningkatkan keunggulan dalam persaingan. Pelanggan yang puas terhadap suatu produk dan jasa, pelanggan cenderung untuk membeli kembali produk dan menggunakan kembali jasa pada saat kebutuhan yang sama muncul kembali dikemudian hari. Hal ini berarti kepuasan merupakan faktor kunci bagi pelanggan dalam melakukan pembelian ulang yang merupakan porsi terbesar dari volume penjualan perusahaan.

Indikator kepuasan pelanggan menurut Hawkins dan Lonney yang dikutip oleh Tjiptono (2007), terdiri atas kesesuaian harapan, minat berkunjung kembali, dan kesediaan merekomendasikan. Kesesuaian harapan merupakan tingkat kesesuaian antara kinerja produk yang diharapkan oleh pelanggan dengan yang dirasakan oleh pelanggan, Minat berkunjung kembali merupakan kesedian pelanggan untuk berkunjung kembali atau melakukan pembelian ulang terhadap produk terkait. Kesediaan merekomendasikan merupakan kesediaan pelanggan untuk merekomendasikan produk yang telah dirasakannya kepada teman atau keluarga.

\section{Kualitas Produk}

Menurut Aaker (1994), kualitas produk adalah persepsi pelanggan terhadap kualitas keseluruhan atau keunggulan produk atau layanan, sehubungan dengan tujuan yang telah ditetapkan, relatif terhadap alternatif (Ehsani dan Ehsani; 2014), sedangkan Kotler dan Amstrong (2012) mendefinisikan kualitas produk adalah karakteristik dari produk atau jasa yang menanggung pada kemampuan untuk memuaskan kebutuhan pelanggan yang dinyatakan atau yang tersirat. Berikut, menurut Alma (2011) adalah seperangkat atribut baik berwujud maupun tidak berwujud, termasuk didalamnya masalah warna, harga, nama baik pabrik, nama baik toko yang menjual (pengecer), dan pelayanan pabrik serta pelayanan pengecer, yang diterima oleh pembeli guna memuaskan keinginannya.

Definisi tersebut dapat disimpulkan bahwa kualitas produk merupakan kadar atau tingkat baik buruknya sesuatu yang terdiri dari semua faktor yang melekat pada barang atau jasa, sehingga produk tersebut memiliki kemampuan untuk 
dipergunakan sebagaimana yang diinginkan pelanggan produk tersebut. Produk yang berkualitas tinggi sangat diperlukan agar keinginan pelanggan dapat dipenuhi. Keinginan pelanggan yang terpenuhi sesuai dengan harapannya akan membuat pelanggan menerima suatu produk bahkan sampai loyal terhadap produk tersebut. Pesaing yang banyak di pasar menuntut perusahaan harus memerhatikan kebutuhan pelanggan, serta berusaha memenuhi kebutuhan itu dengan produk yang bermutu tinggi. Kualitas produk memberikan dorongan kepada pelanggan untuk menjalin ikatan yang kuat dengan perusahaan. Pelanggan akan senang jika kebutuhannya terpenuhi.

Menurut Garvin (1987), indikator kualitas produk terdiri atas kinerja (performance), ciri-ciri atau keistimewaan tambahan (feature), keandalan (reliability), kesesuaian dengan spesifkasi (conformance to specification), daya tahan (durability), kegunaan (serviceability), estetika (aestethic), dan kualitas yang dipersepsikan (perceived quality). Kinerja adalah karakteristik operasi pokok dari produk inti (core product) yang memberikan manfaat bagi pelanggan. Ciri-ciri atau keistimewaan tambahan adalah karakteristik sekunder atau pelengkap dari produk inti yang merupakan tambahan produk yang dijadikan ciri khas yang membedakan dengan produk pesaing yang sejenis. Keandalan adalah kemungkinan kecil terhadap suatu kegagalan pakai atau kerusakan. Kesesuaian dengan spesifkasi adalah sejauh mana karakteristik desain operasi memenuhi standar-standar yang telah ditetapkan sebelumnya. Daya tahan berkaitan dengan berapa lama produk tersebut dapat terus digunakan. Kegunaan (serviceability) meliputi kecepatan, kompetensi, kenyamanan, mudah direparasi, serta penanganan keluhan yang memuaskan. Estetika adalah daya tarik produk terhadap panca indera. Kualitas yang dipersepsikan (perceived quality) meliputi cita rasa, reputasi produk, dan tanggung jawab perusahaan terhadap produk yang dikonsumsi oleh pelanggan".

\section{Citra Merek}

Pengertian merek menurut Ginting (2011), merek (brand) adalah "suatu nama, istilah, tanda, simbol, desain atau kombinasi daripadanya untuk menandai produk atau jasa dari satu penjual atau kelompok penjual dan untuk membedakannya dari pesaing, sedangkan menurut Kotler dan Armstrong (2012), merek adalah nama, istilah, tanda, lambang atau desain, atau kombinasi dari semua ini yang memperlihatkan identitas produk atau jasa dari satu penjual atau sekelompok penjual dan membedakan produk itu dari produk pesaing. Walley (2007), citra merek (brand name) adalah kesan yang dibuat dalam memori konsumen karena adanya keterlibatan konsumen dengan sebuah merek (Arslan, 2014). Citra merek adalah deskripsi tentang asosiasi dan keyakinan pelanggan terhadap merek tertentu" (Tjiptono, 2015), Berdasarkan definisi tersebut, dapat disimpulkan bahwa citra merek merupakan sebagai suatu persepsi yang muncul di benak pelanggan ketika mengingat suatu merek dari produk tertentu. Kotler \& Armstrong (2012), konsumen yang akrab dengan merek, puas dengan kinerja produk akan terus melakukan pembelian pada merek yang dianggap sebagai pilihan yang aman". Dengan program pemasaran yang baik dan kuat akan sedikit demi sedikit tercipta citra merek yang positif dan mudah untuk dikenali (Mustakarillah, 2011).

Indikator yang digunakan untuk mengukur citra merek adalah indikator yang dikemukan oleh Aaker dan Biel (Thamrin, 2012), yaitu citra pembuat (corporate image), citra pemakai (user 
image), dan citra produk (product image). Citra pembuat adalah sekumpulan asosiasi yang dipersepsikan pelanggan terhadap perusahaan yang membuat suatu produk dan jasa, citra pembuat meliputi popularitas, kredibilitas, dan jaringan perusahaan. Citra pemakai adalah sekumpulan asosiasi yang dipersepsikan pelanggan terhadap pemakai yang menggunakan barang atau jasa yang meliputi pemakai itu sendiri dan satus sosial. Citra produk adalah sekumpulan asosiasi yang dipersepsikan pelanggan terhadap suatu produk, yang meliputi atibut produk, manfaat bagi pelanggan, serta jaminannya".

\section{Hipotesis}

1. Kualitas produk berpengaruh positif dan signifikan terhadap kepuasan pelanggan helm merek KYT di Kecamatan Bintara Kota Bekasi.

2. Citra merek berpengaruh positif dan signifikan terhadap kepuasan pelanggan helm merek KYT di Kecamatan Bintara Kota Bekasi.

3. Kualitas produk dan citra merek berpengaruh positif dan signifikan terhadap kepuasan pelanggan helm merek KYT di Kecamatan Bintara Kota Bekasi.

\section{METODE PENELITIAN}

\section{Rancangan Penelitian}

Tujuan penelitian ini adalah untuk menganalisis hubungan kausalitas antara kualitas produk dan citra merek dengan kepuasan pelanggan. Data yang digunakan adalah data primer dengan menyebar kuesioner kepada pengguna helm merek KYT di Kecamatan Bintara Kota Bekasi. Metode analisis data yang digunakan dalam penelitian ini adalah analisis regresi linear sederhana dan regresi linear berganda.

\section{Metode Pengumpulan Data}

Metode pengumpulan data adalah suatu pernyataan tentang sifat keadaan, kegiatan tertentu dan sejenisnya. Pengumpulan data dilakukan untuk memperoleh informasi yang dibutuhkan dalam rangka mencapai tujuan penelitian (Gulo, 2004). Jenis data yang dipergunakan dalam penelitian ini adalah data subyek. Data subjek merupakan jenis data yang digunakan dalam penelitian berupa opini, sikap, pengalaman dari seorang yang menjadi subyek penelitian, yakni pengguna helm merek KYT di Kecamatan Bintara Kota Bekasi. Sumber data yang digunakan dalam penelitian ini adalah data primer. Data Primer merupakan data yang diperoleh atau dikumpulkan langsung di lapangan oleh seseorang atau sekelompok orang yang melakukan penelitian. Data primer ini disebut juga data asli atau data baru. Data ini berisikan antara lain jawaban pertanyaan berupa angket (pernyataan) yang disebarkan kepada seluruh responden.

Populasi adalah sekelompok orang, kejadian atau apa saja yang mempunyai kualitas dan karakteristik tertentu yang ditetapkan peneliti (Razak, 2012), sedangkan menurut Sugiyono (2016), populasi adalah wilayah generalisasi yang terdiri atas: obyek/subyek yang mempunyai kualitas dan karakteristik tertentu yang ditetapkan oleh peneliti untuk dipelajari dan kemudian ditarik kesimpulannya. Sebagai populasi dalam penelitian ini adalah seluruh pelanggan yang membeli serta menggunakan helm merek KYT, di Kecamatan Bintara, Kota Bekasi. Populasi pelanggan helm merek KYT tidak diketahui jumlahnya. Sampel adalah bagian dari populasi (Razak, 2012), sedangkan menurut Sugiyono (2016), sampel adalah bagian dari jumlah dan karakteristik yang dimiliki oleh populasi tersebut. Teknik pengambilan sampel menggunakan teknik purposive sampling dengan pertimbangan 
responden telah berusia 17 tahun keatas, dan menggunakan helm merek KYT selama satu tahun terakhir. Sampel dalam penelitian ini sebanyak 100 responden. Penelitian dilaksanakan selama kurun waktu empat bulan, yaitu dari bulan Januari s/d April 2019. Untuk mempermudah di dalam pengumpulan data, penelitian dilakukan di beberapa toko yang menjual helm merek KYT di Kecamatan Bintara, Kota Bekasi.

\section{Metode Analisis Data}

1. Analisis regresi linear sederhana

Untuk menganalisis pengaruh kualitas produk terhadap kepuasan pelanggan helm merek KYT digunakan analisis regresi linear sederhana yaitu sebagai berikut:

$$
\mathrm{Y}=\mathrm{a}_{1}+\mathrm{b}_{1} \mathrm{X}_{1}
$$

Untuk menganalisis pengaruh citra merek terhadap kepuasan pelanggan helm merek KYT digunakan analisis regresi linear sederhana yaitu sebagai berikut:

$$
\mathrm{Y}=\mathrm{a}_{2}+\mathrm{b}_{2} \mathrm{X}_{2}
$$

2. Analisis regresi linear berganda

Untuk menganilisis pengaruh kualitas produk dan citra merek terhadap kepuasan pelanggan helm merek KYT digunakan analisis regresi linear berganda, yaitu sebagai berikut:

$$
\begin{aligned}
& \quad \mathrm{Y}=\mathrm{a}_{3}+\mathrm{b}_{1} \mathrm{X}_{1}+\mathrm{b}_{2} \mathrm{X}_{2} \\
& \text { dimana } \\
& Y=\text { Kepuasan Pelanggan } \\
& X_{1}=\text { Kualitas Produk } \\
& X_{2}=\text { Citra Merek } \\
& a_{i}=\text { Konstanta }(i=1,2,3) \\
& b_{i}=\text { Koeisinen Regresi }(i=1,2)
\end{aligned}
$$

\section{HASIL PENELITIAN DAN PEMBAHASAN}

\section{Hasil Penelitian}

1. Analisis Regresi Linear Sederhana

Tabel-2: Pengaruh Kualitas Produk TerhadapKepuasan Pelanggan

\begin{tabular}{cccccc}
\hline & \multicolumn{5}{c}{ Parameter } \\
\cline { 2 - 6 } Variabel & $\mathbf{r}$ & $\mathbf{R}^{\mathbf{2}}$ & Konstanta & $\begin{array}{c}\text { Koefisien } \\
\text { Regresi }\end{array}$ & Sig \\
\hline Kualitas Produk & 0,812 & 0,659 & 6,544 & 0,477 & 0,000 \\
\hline
\end{tabular}

Nilai koefisien determinasi $\left(\mathrm{R}^{2}\right)$ sebesar 0.659 , artinya kualitas produk memberikan kontribusi sebesar $65,9 \%$ kepada kepuasan pelanggan helm merek KYT di Kecamatan Bintara Kota Bekasi, sedangkan sisanya sebesar $34,1 \%$ disumbangkan faktor, seperti citra merek. Kualitas produk berpengaruh positif dan signifikan pada tingkat nyata $99 \%$ terhadap kepuasan pelanggan helm merek
KYT di Kecamatan Bintara Kota Bekasi. Koefisien regresi kualitas produk bertanda positif menunjukkan bahwa jika ada peningkatan kualitas produk, maka kepuasan pelanggan helm merek KYT di Kecamatan Bintara Kota Bekasi diduga meningkat atau sebaliknya. Dengan demikian hipotesis-1 teruji. 
Tabel-3: Pengaruh Citra Merek Terhadap Kepuasan Pelanggan

\begin{tabular}{cccccc}
\hline & \multicolumn{5}{c}{ Parameter } \\
\cline { 2 - 6 } Variabel & $\mathbf{r}$ & $\mathbf{R}^{2}$ & Konstanta & $\begin{array}{c}\text { Koefisien } \\
\text { Regresi }\end{array}$ & Sig \\
\hline Citra Merek & 0,758 & 0,575 & 5,898 & 0,960 & 0,000 \\
\hline
\end{tabular}

Nilai koefisien determinasi $\left(\mathrm{R}^{2}\right)$ sebesar 0.575, artinya citra merek memberikan kontribusi sebesar $57,5 \%$ kepada kepuasan pelanggan helm merek KYT di Kecamatan Bintara Kota Bekasi, sedangkan sisanya sebesar $42,5 \%$ disumbangkan oleh faktor lain, seperti kualitas produk dan sebagainya. Citra merek berpengaruh positif dan signifikan pada tingkat nyata $99 \%$ terhadap kepuasan pelanggan helm merek KYT di Kecamatan Bintara Kota Bekasi. Koefisien regresi citra merek bertanda positif menunjukkan bahwa jika ada peningkatan citra merek, maka kepuasan pelanggan helm merek KYT di Kecamatan Bintara Kota Bekasi diduga meningkat atau sebaliknya. Dengan demikian hipotesis-2 teruji.
2. Analisis regresi linear berganda

Nilai F Fitung sebesar 136,079, artinya secara bersama-sama kualitas produk dan citra merek berpengaruh signifikan pada tingkat nyata $99 \%$ terhadap kepuasan pelanggan helm merek KYT di Kecamatan Bintara Kota Bekasi. Nilai koefisien determinasi $\left(\mathrm{R}^{2}\right)$ sebesar 0.737 , artinya kontribusi kualitas produk dan citra merek kepada kepuasan pelanggan sebesar $73,7 \%$, sedangkan sisanya sebesar $23,6 \%$ disumbangkan faktor lain yang tidak dibahas dalam penelitian ini, seperti harga, dan sebagainya.

\section{Tabel-4: Pengaruh Kualitas Produk dan Citra Merek Terhadap Kepuasan Pelanggan}

\begin{tabular}{lccccc}
\hline \multirow{2}{*}{ Variabel } & \multicolumn{5}{c}{ Parameter } \\
\cline { 2 - 6 } & $\begin{array}{c}\text { Mult. } \\
\text { R }\end{array}$ & $\mathbf{R}^{\mathbf{2}}$ & Konstanta & $\begin{array}{c}\text { Koefisien } \\
\text { Regresi }\end{array}$ & Sig \\
\hline Kualitas Produk & & & & 0,324 & 0,000 \\
Citra Merek & 0,859 & 0,737 & 0,776 & 0,483 & 0,000 \\
& & & & & \\
\hline Fhitung $=136,079>\mathrm{F}_{\text {tabel }}=3,090$ & & & \\
\hline
\end{tabular}

Kualitas produk dan citra merek berpengaruh positif dan signifikan terhadap kepuasan pelanggan helm merek KYT Kecamatan Bintara Kota Bekasi, pada tingkat nyata $99 \%$. Koefisien regresi kualitas produk bertanda positif menunjukkan bahwa jika ada peningkatan kualitas produk, maka kepuasan pelanggan helm merek KYT di Kecamatan Bintara Kota Bekasi diduga meningkat atau sebaliknya dengan asumsi citra merek tidak berubah. Koefisien regresi citra merek bertanda positif menunjukkan bahwa jika ada peningkatan citra merek, maka kepuasan pelanggan helm merek KYT di Kecamatan Bintara Kota Bekasi diduga meningkat atau sebaliknya dengan asumsi kualitas produk tidak berubah. Dengan demikian hipotesis-3 teruji.

\section{Pembahasan}

1. Pengaruh Kualitas Produk Terhadap Kepuasan Pelanggan

2. 
Hasil penelitian ini menunjukkan bahwa kualitas produk mendorong peningkatan kepuasan pelanggan. Hal ini dikarenakan helm merek KYT memberi manfaat bagi pengguna, nyaman bila digunakan, produknya memiliki perbedaan dengan produk pesaing, memiliki daya tarik tersendiri, resiko kerusakan lebih kecil, sesuai dengan standar nasional (SNI), sesuai dengan selera yang diinginkan, memiliki daya tahan yang lama walaupun sering digunakan, berguna untuk melindungi pengendara motor, dan dapat dipertanggung jawabkan. Hasil penelitian ini sesuai dengan penelitian yang dilakukan oleh Basith, et al (2003), Hidayat (2009), Jahanshahi, et al (2011), Suwarni dan Mayasari (2011), Jakpar, et al (2012), Saidani dan Arifin (2012), Senthilkumar (2012), Ismail (2014), Kusuma, et al (2014), Sembiring, et al (2014), Yesenia dan Siregar (2014), Hayati dan Sekartaji (2015), Adelina (2016), Atiyah (2016), Sitanggang, et al (2019), dan Razak (2019), yang menganalisis pengaruh kualitas produk terhadap kepuasan pelanggan.

3. Pengaruh Citra Merek Terhadap Kepuasan Pelanggan

Hasil penelitian ini menunjukkan bahwa citra merek mendorong peningkatan kepuasan pelanggan. Hal ini dikarenakan bahwa helm merek KYT sudah lama dikenal oleh pelanggan, mendapat kepercayaan dari pelanggan bahwa helm merek KYT dapat melindungi kepala jika terjadi kecelakaan, memiliki jaringan yang luas, berkualitas dan berstandar nasional. Hasil penelitian ini sejalan dengan penelitian yang dilakukan oleh Kambiz, et al (2014), Tombukan, et al (2015), Anung (2012), dan Tangguh, et al (2018), yang menganalisis pengaruh citra merek terhadap kepuasan pelanggan.

4. Pengaruh Kualitas Produk dan Citra Merek Terhadap Kepuasan Pelanggan

Hasil penelitian menunjukkan bahwa kualitas produk dan citra merek secara bersama-sama mendorong peningkatan kepuasan pelanggan helm merek KYT. Hasil penelitian ini mendukung hasil penelitian yang dilakukan oleh Kurniawati, et al (2014), Halim, et al (2014), Adelina (2016), Widiaswara, et al (2017), yang menganalisis pengaruh kualitas produk dan citra merek terhadap kepuasan pelanggan.

\section{KESIMPULAN DAN SARAN}

\section{Kesimpulan}

1. Kualitas produk mendorong peningkatan kepuasan pelanggan helm merek KYT di Kecamatan Bintara Kota Bekasi.

2. Citra merek mendorong peningkatan kepuasan pelanggan helm merek KYT di Kecamatan Bintara Kota Bekasi.

3. Kualitas produk dan citra merek secara bersama-sama mendorong peningkatan kepuasan pelanggan helm merek KYT di Kecamatan Bintara Kota Bekasi.

\section{Saran}

Produk helm merek KYT yang sudah cukup dikenal harus tetap dijaga, ikutin terus perkembangan produk helm yang lebih modern, lakukan inovasi agar produk yang sudah ada lebih nyaman digunakan oleh para pengendara motor.

1. Perusahaan harus tetap mempertahankan merek helm yang sudah cukup dikenal oleh masyarakat, dan yang perlu dijaga adalah perusahaan harus dapat mempertahan kualitas produknya, buat pemakai helm lebih nyaman lagi dalam menggunakannya. 
2. Bagi peneliti selanjutnya disarankan untuk menambah variabel-variabel lain yang lebih beragam dalam membahas terkait kepuasan konsumen dalam membeli helm.

\section{DAFTAR PUSTAKA}

Aaker, David A, and Alexande L. Biel. 2009. Brand Equity and Advertising: Advertising Role in Building Strong Brands. Lawrence Erlbaum Associates, Inc, Hillsdale.

Adelina. 2016. Pengaruh Citra Merek dan Kualitas Produk terhadap Kepuasan Pelanggan Sabun Mandi Merek Lifebuoy di Footmart Samarinda. Jurnal Administrasi Bisnis. 4(1). 76-87.

Alfin, R., 2013, Mediation Effects on Customer Satisfaction and Service Quality Products Quality Customer Loyalty, Interdisciplinary Journal of Contemporary Research in Business, Vol. 5, No. 6, October, 735-744.

Alma, Buchari. 2011. Manajemen Pemasaran dan Pemasaran Jasa. Bandung: Penerbit Alfabeta.

Anung, P. 2012. Pengaruh Citra Merek terhadap Loyalitas melalui Kepuasan sebagai Intervening (Studi pada Mahasiswa Perguruan Tinggi Swasta di Yogyakarta. JBMA. Vol. 1, No. 1.

Arslan, Muhammad dan Rashid Zaman. 2014. "Impact of Brand Image and Service Quality on Consumer Purchase Intentions. A Study of Retail Stores in Pakistan." Research on Humanities and Social Sciences, Vol. 4, No. 22, pp. 98-107.

Atiyah, L., 2016, Product's Quality and Its Impact on Customer Satisfaction a Field Study in Diwaniyah Dairy Factory, Proceedings of The $10^{\text {th }}$ International Management Conference, Challenges of Modern
Management, November $3^{\text {nd }}-4^{\text {th }}$, Bucharest, Romania, 57-65.

Baker, M.J., 2003, Marketing Book, $5^{\text {th }}$ Edition, Oxford, Buttterworth Heinemann.

Basith, A. Kumadji, S. dan Hidayat, K. 2014. Pengaruh Kualitas Produk dan Kualitas Pelayanan terhadap Kepuasan Pelanggan dan Loyalitas Pelanggan (Survey pada Pelanggan De'Pans Pancake and Waffle di Kota Malang). Jurnal Administrasi Bisnis. Vol. 11, No. 1, Juni, 1-8.

Bei, L.T., \& Chiao, Y.C., 2001, An Integrated Model for The Effects of Perceived Product, Perceived Service Quality, and Perceived Price Fairness on Consumer Satisfaction and Loyalty, Journal of Consumer Satisfaction, Dissatisfaction and Complaining Behavior, Vol.14, 125-140.

Burnett, J., 2008, Core Concepts of Marketing, Switzerland, Jacobs Foundation.

Cahyadi, E. 2007. Analisa Kualitas Produk, dan Persepsi Harga terhadap Loyalitas Pelanggan Mc Donald's di Semarang. Thesis, Universitas Stikubank Semarang.

Choi, E.J., \& Kim, S.H, 2013, The Study of the Impact of Perceived Quality and Value of Social Enterprises on Customer Satisfaction and RePurchase Intention, International Journal of Smart Home, Vol.7, No.1, 239-251.

Diansyah. 2016. Pengaruh Kualitas Produk dan Citra Merek terhadap Kepuasan Konsumen Laptop Lenovo dengan Inovasi Produk sebagai Variabel Moderator. Media Studi Ekonomi.Vol.19, No.2, JuliDesember.15-29.

Djumarno, Sjafar, O., \& Djamaluddin, 2017, The Effect of Brand Image, Product Quality, and Relationship Marketing on Customer Satisfaction and Loyalty, 
International Journal of Business Marketing and management, Vol.2, Issue 10, November, 15-24.

Ehsani, Z., \& Ehsani, M.H., 2015, Effect of Quality and Price on Customer Satisfaction and Commitment in Iran Auto Industry, International Journal of Service Sciences, Management and Engineering. 1(5), 52-56.

Fornell, C., Johnson, M,D., Anderson, E,W., Cha, J, \& Bryant, B,E., 1996, The American Custumer Satisfaction Index: Nature, Purpose, anaction Index: Nature, Purpose, and Findings, Journal of Marketing, Vol. 60, 7-18.

Garvin, D.A., 1987, Competing on the Eight Dimensions of Quality, Harvard Business Review, November-December, 101-109.

Ginantra, K.G., Lestari, N.P.N.E., Gorda, E.S., \& Darma, G.S., 2017, Effect of Promotion, Product Quality, Brand Image and Price on Customer Satisfaction and Brand Switching Decision (A Case Study on XI Cellular Card Users in Denpasar City, Bali, Indonesia), International Journal of Management and Economic Invention, Vol.3, Issue.12, Dec, 1514-1523.

Halim, P., Swasto, B., Hamid, D., \& Firdaus, M.R., 2014, The Influence of Product Quality, Brand Image, and Quality Service to Customer Trust, and Implication on Customer Loyalty (Survey on Customer Brand Sharp Electronics Product at The South Kalimantan Province), European Journal of Business and Management, Vol.6, No.29, 159166.

Hayati, Y.H dan Sekartaji, G. 2015. Pengaruh Kualitas Produk terhadap Kepuasan Konsumen di Restoran Bebek dan Ayam Goreng Pak NDut Solo. Jurnal Ilmiah Manajemen
Fakultas Ekonomi (JIMFE). Vol.1. No.1. 49-56.

Hermawan, B. 2011. Pengaruh Kualitas Produk terhadap Kepuasan, Reputasi Merek, dan Loyalitas Konsumen Jamu Tolak Angin PT. Sido Muncul. Jurnal Manajemen Teori dan Terapan. Tahun 4. No.2. Agustus. 9-17.

Hidayat, R. 2009. Pengaruh Kualitas Layanan, Kualitas Produk, dan Nilai Nasabah terhadap Kepuasan dan Loyalitas Nasabah Bank Mandiri. Jurnal Manajemen dan Kewirausahaan. Vol.11. No.1. Maret. 59-72.

Hill, N., 1996, Handbook of Customer Satisfaction Measurement, England, Gower Publishing.

Indarto, E W,. Suroso, I dan Sudaryanto, (2018). "Pengaruh Citra Merek dan Atribut Produk Terhadap Kepuasan Konsumen dan Loyalitas Konsumen". Journal of Applied Management (JAM), Volume 16. Number 3, September 2018.

Irawan, H. 2008. Sepuluh Prinsip Kepuasan Pelanggan. Jakarta. Penerbit Elex Media Komputindo Kelompok Gramedia.

Ismail, R. 2014. Pengaruh Kualitas Layanan, Kualitas Produk dan Kepuasan Nasabah sebagai Preditor dalam Meningkatkan Loyalitas Nasabah. Jurnal Organisasi dan Manajemen. Vol. 10, No. 2, September. 179-196.

Jahanshahi, A.A., Gashti, M.A.H., Mirdamadi, S.A., Nawaser, K, \& Khaksar, S.M.S., 2011, Study of Effects of Customer Service and Product Quality on Customer Satisfaction and Loyalty, International Journal of Humanities and Social Science, Vol.1, No.7, (June), 253-260.

Jakpar, S., Na, A.G.S., Johari, A., \& Myint, K.T., 2012, Examining the 
Product Quality Attributes That Influences Customer Satisfaction Most When the Price Was Discounted: A Case Study in Kuching Sarawak, International Journal of Business and Social Science, Vol.3, No. 23, December, 221-236.

Jayanti, E, Samsir, dan Musfar, T.F. 2018. Pengaruh Kualitas Produk dan Citra Merek terhadap Kepuasan Konsumen dan Loyalitas Pelanggan pada Produk Kecantikan Merek Make Over di Kota Pekan Baru. JOM FEB. Vol.1. Edisi-1. JanuariJuni. 1-15.

Kambiz, S., \& Safoura, N. S. 2014. The Impact of Brand Image on Customer Satisfaction and Loyalty Intention (Cash Study; Consumer of Hygiene Products). International Journal of Engineering Innovation \& Research. Vol. 3, Issue 1, 57-61.

Khan, L.M., \& Ahmed, R., 2012, A Comparative Study of Consumer Perception of Product Quality: Chinese versus Non-Chinese Products, Journal of PJETS, 2(June), 118-143.

Khan, M. N., Aabdean, Z., Salman, M,. Nadeem, B., \& Rizwan, M., 2016, The Impact of Product and Service Quality on Brand Loyalty: Evidence from Quick Service Restaurants, American Journal of Marketing Research, Vol.2, No.3, 84-94.

Kotler, P., 1972, A Generic Concept of Marketing, Journal of Marketing, Vol. 36, No. 2, 46-54.

, \& Amstrong, G., 2012, Principle of Marketing, $14^{\text {th }}$ Edition. New Jersey, Published by Prentice Hall.

., \& Keller, K.L., 2012, Marketing Management, $14^{\text {th }}$ Edition, New Jersey, Published by Prentice Hall.
Kurniawati, D, Suharyono dan Andriani, K. 2014. "Pengaruh Citra Merek dan Kualitas Produk Terhadap Kepuasan dan Loyalitas Pelanggan”. (Studi Pada Pelanggan KFC Cabang Kawi Malang). Jurnal Administrasi Bisnis (JAB), Vol. 14 No. 2 September 2014.

Kusuma, N.P., Suyadi, I., \& Abdillah, Y., 2014, Analyzing The Effect of Product Quality on Customer Satisfaction and Customer Loyalty in Indonesian SMEs (Case Study on the Customer of Batik Bojonegoro Marely Jaya), Jurnal Administrasi Bisnis (JAB), Vol.14, No.1, September, 1-7.

Lonardo dan Soelasih, Y. 2014. Analisis Pengaruh Kualitas Produk, Harga, Lingkungan Fisik Perusahaan Kue Lapis Legit XYZ terhadap Kepuasan Konsumen dalam Membangun Word of Mouth Positif. Jurnal Manajemen. Vol. 11. No. 1. Mei 2014. 27-40.

Milfelner, B., Snoj, B., \& Korda, A.P., 2009, Measurement of Perceived Quality, Perceived Value, Image, and Satisfaction Interrelations of Hotel Services: Comparison of Tourists From Slovenia and Italy, Slovenia, Faculty of Economics and Business, University of Maribor.

Mulyono, B.H, Yoestini, Nugraheni, R, dan Kamal, M. 2007. Analisis Pengaruh Kualitas Produk dan Kualitas Layanan terhadap Kepuasan Konsumen (Studi Kasus pada Perumahan Puri Mediterania Semarang). Jurnal Studimanajemen \& Organisasi. Vol.4. No.2 Juli. 91-100.

Munisih, S dan Soliha, E. 2015. Pengaruh Kualitas Produk terhadap Nilai Pelanggan dan Kepuasan Pelanggan dan Dampaknya pada Loyalitas Pelanggan Apotek Dela 
Semarang. Prosiding Seminar Nasional \& Call for Papers. Semarang. Fakultas Ekonomika dan Bisnis Universitas STIKUBANK Semarang.

Nindiani, A., Hamsal, M., \& Purba, H.H., 2018, Product and Service Quality Analysis: An Empirical Study of Customer Satisfaction in a Bakery, Binus Business Review. 9(2), July, 95-103.

Putro, S.W, Samuel, H, Karina, R, dan Brahmana. 2014. Pengaruh Kualitas Layanan dan Kualitas Produk terhadap Kepuasan Pelanggan dan Loyalitas Konsumen Restoran Happy Garden Surabaya. Jurnal Manajemen Pemasaran. Vol.2, No.1, 1-9.

Rangkuti, F., 2002, Measuring Customer Satisfaction, Jakarta Gramedia Pustaka Utama.

Razak, I. 2014. Manajemen Pemasaran. Cetakan ke-3. Surabaya. Penerbit CV. Perwira Media Nusantara. , Junaedi, A, dan Hakim, L. 2012. Metodologi Penelitian Ekonomi \& Bisnis: Ekonomi, Manajemen, dan Akuntansi. Edisi Pertama, Cetakan ke 1. Jakarta. Penerbit Pranada.

., Nirwanto, N., \& Triatmanto, B., 2016, The Impact of Product Quality and Price on Customer Satisfaction with the Mediator of Customer Value, Journal of Marketing and Consumer Research, Vol.30, 59-68. 2019, Pengaruh Kualitas Produk terhadap Kepuasan Pelanggan. Jurnal Manajemen Bisnis Krisnadwipayana. Vol. 7, No.2, Mei-Agustus, 1-14.

Rizwan, M., Umair, M.A., Fiaz, A., \& Rashid, Q., 2014, Determinant of Customer Satisfaction and its Impact on Customer Loyalty in Nokia Brand, Journal of
Sociological Research, Vo.5, No.1, 430-448.

Sacednia, H.R., \& Valahzzaghard, S.K., 2012, A Study to Measure The Impact of Customer Perception, Quality, Environment Concern and Satisfaction on Green Customer Loyalty, Management Science Letters, 2881-2888.

Saidani, B dan Arifin, S. 2012. Pengaruh Kualitas Produk dan Kualitas layanan terhadap Kepuasan Konsumen dan Minat Beli pada Ranch Market. Jurnal Riset manajemen Sains Indonesia.Vo.3. No.1. 1-22.

Sakaran, U., 2003, Research Method for Business, $4^{\text {th }}$ edition, New York, Jhon Wiley \& Sons Inc.

Saparuddin, 2016. Pengaruh Kualitas Produk dan Brand Image terhadap Kepuasan Konsumen dan Loyalitas Pelanggan Kamera Canon Digital Single Lens Reflex (Studi Kasus Komunitas Pontianak Photografer Community). Jurnal Manajemen Pemasaran. Agustus, 1-14.

Schiffman, L.G., \& Kanuk, L.L., 2004, Consumer Behavior, $8^{\text {th }}$ Edition, New Jersey, Prentice Hall.

Sembiring, I.J, Suharyono, dan Kusumawati, A. 2014. Pengaruh Kualitas Produk dan Kualitas Pelayanan terhadap Kepuasan Pelanggan dalam Membentuk Loyalitas Pelanggan. Jurnal Administrasi Bisnis. Vol. 15, No. 1. Oktober. 1-10.

Senthilkumar, V., 2012, A Study on The Effects of Customer Service and Product Quality on Customer Satisfaction and Loyalty, Namex International Journal of Management Research, Vol. 2. No. 2. 123-129.

Shum, Y.Y., 2010, The Effect of Perceived Product Quality and Perceived Service Quality on Customer Satisfaction and Loyalty 
in Fast Fashion Relailers, Thesis. Hong Kong. The Hong Kong Polytechnic University.

Sitanggang, J.M., Sinulingga, S., and Fachrudin, K. A., 2019, Analysis of The Effect of Product Quality on Customer Satisfaction and Loyalty of Indihome ATPT Telkom Regional 1 Sumatera, Medan, North Sumatera, Indonesia, American International Journal of Business Management (AIJBM), Vol.2, Issue 3, March, 26-37.

Sreevidya, U., \& Ottuparammal, S. V., 2011, Marketing Management, Calicut University PO Malappuran, Kerala, India.

Suchanek, P., Richter, J., \& Kralova, M., 2014, Customer Satisfaction, Product Quality and Performance of Companies. Review of Economic Perspectives, Vol. 14, Issue 4, 329344.

Sugiyono. 2016. Statikstika Untuk Penelitian. Bandung. Penerbit Alfabeta.

Suwarni dan Mayasari, S. D. 2011. Pengaruh Kualitas Produk dan harga terhadap Loyalitas Melalui Kepuasan Konsumen. Jurnal Ekonomi Bisnis. Th.16. No.1. 7884.

Tangguh, G, G, W., Pangestuti, E., dan Nuralam, I, P. 2018. Pengaruh Citra Merek, Kualitas Layanan, dan Harga terhadap Kepuasan Pelanggan Go-Ride. Jurnal Administrasi Bisnis, Vol. 61, No. 2, Agustus, 118-126.

Thamrin, A, dan Tantri, F. 2012. Manajemen Pemasaran. Depok : Penerbit PT Raja Grafindo Persada

Tjiptono, F. 2007. Strategi Pemasaran. Edisi ke-2. Yogyakarta. Penerbit Andi.

Tombukan, F., Kawet, L,. dan Uling, Y. (2015). Pengaruh Kualitas Layanan, Citra Merek terhadap
Kepuasan Konsumen Pengguna Taplus BNI Cabang Utama Menado. Jurnal EMBA, Vol. 3, No. 3, September, 552-561.

Tsiotsou, R., 2006, The Role of Perceived Product Quality and Overall Satisfaction on Purchase Intentions, International Journal of Consumer Studies, March, 207-217.

Tu, Y.T., Li, M.L., \& Chih, H.C., 2013, An Emperical Study of Corporate Brand Image, Customer Perceived Value and Satisfaction on Loyality in Shoes Industry, Journal of Economic and Behavioral Studies, Vol.5 No.7 (July), 469-483.

Umar, H. 2005. Riset Pemasaran dan Perilaku Konsumen. Jakarta : Penerbit PT. Gramedia Pustaka Utama.

Wenur, C, Mandey, S dan Tumbuan, W.A. 2015. Pengaruh Strategi Green Marketing, Citra Merek dan Kualitas Produk terhadap Kepuasan Konsumen Pengguna The Body Shop, Manado Town Square. Jurnal EMBA. Vol.3. No.2. Juni. 283-293.

Widiaswara, Tias dan Sutopo. 2017. "Analisis Pengaruh Kualitas Produk dan Citra Merek Terhadap Loyalitas Pelanggan Melalui Kepuasan Pelanggan Sebagai Variabel Intervening". (Studi Pada Pelanggan Air Minum Dalam Kemasan Club di Semarang). Diponegoro Journal of Management, Volume 6, Nomor. 4, Tahun 2017, Halaman 1-15, ISSN (Online): 2337-3792.

Yamit, Z. 2013. Manajemen Kualitas Produk dan Jasa. Cetakan Keenam. Yogyakarta. Penerbit Ekonisia.

Yesenia dan Siregar, E. H. 2014.Pengaruh Kualitas Layanan dan Produk terhadap Kepuasan serta Loyalitas Pelanggan Kentucky Fried Chicken di Tanggerang Selatan. Jurnal Manajemen dan 
Organisasi. Vol.V. No.3. Desember 2014. 183-199.

Zeithaml, V.A., 1988, Consumer Perceptions of Price, Quality, and
Value: A Means-End Model and Synthesis of Evidence, Journal of Marketing, Vol, 52 (July), 2-22. 